\title{
A PRODUTIVIDADE DO MITO
}

\author{
Custódio Luís S. de Almeida*
}

SIINTESE - Este artigo é uma tentativa de mostrar, a partir de Gadamer, que o Mito está em estreita relação dialética com o Logos e que a compreensão de ambos pertence a um mesmo movimento circular e hermenêutico, que conecta os conceitos de indeterminado e determinado, incerto e certo, ininitude e finitude.

PAIAVRAS-CHAVE - Gadamer, hermenêutica, mito, logos, dialética, movimento circular.
ABSTRACT - This article is an attempt of showing, starting from Gadamer, that the Myth is in narrow dialectic relationship with Logas and that the understanding of both it belongs to the same movement to circulate and hermeneutic, that connects the concepts of determination and in-determination, uncertain and certain, infinite and finite.

KEY WORDS - Gadamer, hermeneutic, myth, Iogos, dialectic, circular movement.

"Podemos continuar projetando toda a Iuz que disponos sobre as obscuridades da primitiva história da alma humana, mas sua capacidade sonhadora continua sendo seu poder mais forte" (H. Georg Gadamer).

Durante muitos séculos o pensamento ocidental - filosófico e religioso - não considerou o mito ${ }^{1}$ tema de investigação. Certamente o logos, ${ }^{2}$ que "ocupara" seu

* Professor da Universidade Federal do Ceará e doutorando no Curso de Pós-Graduação em Fìlosofia da PUCRS.

1 "A palavra mythos é una palavra grega. No antigo uso lingüístico homérico não quer dizzer ontra coisa que 'discurso', 'proclamação', 'notificação', 'dar a conhecer uma noticia'. Neste uso lingüistico nada indica que esse discurso chamado mythos fosse pouco confiável ou que fosse mentira ou pura invenção, mas muito menos que tivesse alga a ver com o divino.[...] Somente séculos depois, no curso da Ilustração grega, o vocabulário épico de mythos e mythein caj em desuso e é suplantado pelo campo semântico do logos e logein. Mas justamente com isso se estabelece o perfil que cunha o conceito de mito e ressalta o mythos como um tipo particular de discurso frente ao logos, frente ao discurso explicativo e demonstrativo. A palavra designa em tais circunstâncias tudo aquilo que sô pode ser narrado, as histórias dos deuses e dos filhos dos deuses" Cf. Gadamer, Mito e razăo, p. 25.

2 Descle Parmênides e Heráclito, o logos passa a ocupar o lugar que pretende dar conta da narração autentica do mundo. Originariamente, a palavra logos significa "reunir", "contar". Segundo Gadamer, a palavra logos "remete ao âmbito racional dos números e das relações entre números", nesse âmbito o conceito de logos se constitui pela primeira vez e "encontra-se na matemática e na teoria da música da ciência pitagórica. A partir deste âmbito se generaliza a palavra logos cono conceito contrário a mythos" (Cí. Gadamer, Mito y Razón, p. 25). Dentro dessa tradição o logos se acupa da Ciência - saber fundado na demonstração e na prova - e mito é a expressão do "saber" que se anuncia para além da ciência, um tipo particular de discurso frente ao logos. 
lugar no início da filosofia, relegava-o à obscuridade por considerá-lo ingênuo e carente de razão. A razão crítica (filosófica e científica) teve a pretensão de suplantar aqueles tempos em que o mundo sustentava-se na tensa relação entre as forças do Bem e do Mal, da Razão e da Irrazão. Os deuses foram secularizados e a razão "ocupara" o lugar da mitologia.

No entanto, o mito foi redescoberto; ${ }^{3}$ a razão secular tornou a revalorizá-lo; agora a sua força não reside mais em explicações fantásticas sobre a origem do mundo e o equilibrio da vida, mas no seu potencial para fecundar a imaginação e gerar a força especulativa do diálogo. Mas uma pergunta logo se coloca: por que o mito é revalorizado exatamente no período em que a Ilustração foi levada à radicalidade? Pode-se dizer que, no século XX, vivemos um terceiro movimento ilustrado, ou, colocando de outro modo, o tempo em que as conseqüências da Ilustração moderna atingiram seu ponto mais alto, através da burocratização e tecnificação do mundo. O século XX é o século em que se instala plenamente o ateísmo gestado no século anterior e, paradoxalmente, é o tempo da retomada do mítico e da eclosão de forte misticismo.

Olhando para a Ilustração grega, percebemos que no debate com os Sofistas, a Ilustração Antiga pode ser explicada pela oposição entre a narração míticopoética e a discussão racional-filosófica, apresentada por Platão na forma de diálogo (dialética). Platão nos diz que os filósofos são os "amadores do espetáculo da verdade", que se opõem aos "amadores de audições enganosas". Os primeiros se ocupam da dialética e os últimos de narrações retóricas. ${ }^{4}$ No entanto, a Ilustração grega não se caracterizou como negação do mito, mas como valorização da razão como instância indispensável para a compreensão da natureza e da cultura, bem como para a tomada de posição frente à organização social da vida; tanto que Platão, em seus diálogos, coloca o mito não apenas como imagem ilustrativa, mas, muitas vezes, como ápice do logos.

Soma-se a isso o fato do Cristianismo ter contraposto fé e mito e aproximado fé e razão. A secularização do Cristianismo provocou uma negação do mito e o apresentou como sendo incompativel com a fé. Gadamer nos diz que "não tem nenhum sentido falar de fé em relação com um mito ou com histórias miticas, porque visto do ponto de vista da fé, as narrações míticas se encontram para além da pergunta acerca de se algo aconteceu realmente ou não". ${ }^{5} \mathrm{~A}$ fé religiosa exige

3 O século XVIII redescobriu o mito a ponto de, mais tarde, Nietzsche tê-lo como condição vital para qualquer cultura. A revalorização do mito aconteceu a partir do pensamento historiográfico. Vico e Herder teriam sido os precursores, aqueles que abriram caminho para a revalorização romântica posterior. O Romantismo pode ser entendido como o pensamento que encontra no passado a fonte de toda verdade. Gadamer nos diz que "por romantismo entendemos todo o pensamento que conta com a possibilidade de que a verdadeira ordem das coisas não é hoje e nem será no futuro, mas que foi em outro tempo e que, da mesma maneira, o conhecimento de hoje e de amanhã não alcança as verdade que foram conhecidas em outro tempo" (Cf. Gadamer, Mito y Razón, p. 15). Nesse sentido, o mito é revalorizado como sendo portador dessa verdade do passado, não acessível à explicação racional. Podemos dizer que o pensamento historiográfico que redescobriu o mito, encontra sérias dificuldades para a reconstrução historiográfica do mito, já que "segundo sua própria essência, o mito nunca é acessivel em sua pureza original", além de ser oriundo de uma tradição oral - anterior aos registros da escrita - podendo, apenas indiretamente, ser investigado.

5 Cf. Gadamer, Mito y Razón, p. 37. 
o vínculo daquele que acredita com o acontecimento vinculante - no caso do Cristianismo, a encarnação e a ressurreição do Cristo. Já o mito não enfatiza um acontecimento que deve ser tomado como verdadeiro, pois o mais importante não é a verdade ou falsidade do que é narrado; importa sim trazer o ouvinte à participação naquela história, envolvê-lo com ela no presente. Por isso, a racionalização da fé religiosa pelo Cristianismo preparou a secularização do mundo moderno. A Ilustração moderna criou o "sujeito" e fundamentou nele a explicação racional do mundo, levando-a às últimas conseqüências; mas um paradoxo se põe: o "sujeito" que fundamenta não é capaz de fundamentar-se a si mesmo. A revalorização do mito se dá no momento desse impasse da razão, portanto, não pode mais ser considerado patético pensar-se que o "sujeito" que pensa, demonstra e explica é filiado à mesma substancialidade de onde provém o mito - ambos carecem de fundamentação - assim, "em um sentido muito mais amplo, o 'mítico' é o que guarda a verdadeira substância da vida de uma culturax" , 6 por isso, se o mito não serve para fundamentar, pelo menos lembra que toda subjetividade pertence a uma substancialidade que a determina.

Nosso propósito aqui é apresentar esse lugar comum entre mito e logos no início da filosofia ocidental, para que seja possivel a compreensão do reencontro que se estabelece hoje entre esses dois horizontes de compreensão do homem e do mundo. A tese que nos move é: a filosofia é, originariamente, diálogo e diálogo é imerso em tradições; por isso, perseguiremos a idéia de que, no berço da filosofia ocidental, a compreensão da vida se dava, ao mesmo tempo, de modo hermenêutico e dialético.

Os mitos são narrados e a narração exige a presença atenta do narrador e do ouvinte, somente nesse momento privilegiado de sua narração, o mito se efetiva. A circularidade que se constitui entre mito, narrador e ouvinte já denuncia a pertença a um "universo" comum. Aqui, efetivação é atualização; a velha história, cuja origem remonta a tempos esquecidos, se faz novamente atuai e, como tal, não é mais velha história, mas é uma nova experiência, revitalizada em um novo tempo histórico e numa nova linguagem.

O logos ganhou força e ocupou um lugar, talvez, sem volta; não se pode dizer, no entanto, que a razão sepultou o mito, mas sim que sempre o traz resguardado no centro especulativo da linguagem. Isso se nos mostra com a retomada dos estudos da mitologia na contemporaneidade e com a redescoberta da força sensibilizadora e mobilizante da narração de um mito. $O$ recurso ao mito se torna a porta de entrada para a compreensão racional de muitos temas da filosofia e das ciências. O mito não é pressuposto para nenhum conhecimento, mas pode ser um produtivo ponto de partida para o diálogo filosófico ou para uma investigação científica.

O mito e o logos não podem ser separados, pois há uma dimensão comum a ambos: o núcleo especulativo da linguagem. Atualmente, esta tese ganha força após a virada lingüística, pragmática e hermenêutica da filosofia contemporânea. A linguagem se constitui como o centro - começo, meio e fim - da especulação

6 Cf. Gadamer, Mito y Razón, p. 46. 
filosófica; ${ }^{7}$ a pragmática nos mostra que a atualização de uma tese só é possivel através de sua aplicação temporal e histórica, o que pode provocar sua reafirmação ou disrupção; a hermenêutica nos trouxe a idéia do círculo da compreensão, no qual a relação que se estabelece entre o "eu" e o "outro" torna possivel a experiência radical da finitude, que traz ao homem a consciência históricoontológica de inacabamento e, por conseguinte, de ser uma permanente tarefa.

Platão é um genuino ponto de partida; ele tanto faz parte do começo do pensamento filosófico ocidental quanto é o filósofo grego antigo que mais nos deu a conhecer o mundo mitico que o precedeu. Em Platão a filosofia é apresentada em forma de diálogo e 0 diálogo se constitui como plataforma central da atividade filosófica. Mas, de onde Platão recebeu essa inspiração, ou, de quem Platão herdou o seu modo de fazer filosofia? Essa questão inicial nos conduz à investigação sobre o seu tempo histórico, tempo em que mito e logos mantinham relação estreita; ${ }^{8}$ tempo de transição entre a cultura da oralidade e da escritura, em que a relação entre o humano e o divino se dava com toda força; daí a divinização da Sabedoria ${ }^{9}$ e do Bem como princípios filosóficos supremos.

Platão criou na filosofia um estilo literário que se aproximava da cultura oral de seu tempo. Já sabemos que os diálogos de Platão foram escritos para o público em geral, portanto, sua concepção estava marcada pela longa tradição de seus antepassados. É importante, para o entendimento da relação entre mito e logos, que partamos da análise do modo de transmissão da mitologia. Então, a pergunta agora é: como o mito chega até nós, como se propaga? Responder a essa questão pode ser a chave para a compreensão da passagem da forma poético-mítica da narração à forma dialética da filosofia de Platão.

O mito se propaga pela narração, ou seja, a forma da narração é própria do mito e sua estrutura tem uma lógica determinada $\mathrm{O}$ mito conta a histónia da origem dos deuses, do mundo e dos homens, mas não tem paternidade, seu início se perde no tempo; talvez por isso mesmo, o tempo, na mitologia, tenha se tornado um mito, já que não cabe a pergunta pela origem do tempo: a palavra origem já é filha do tempo e só no tempo encontra significação. O mito é, portanto, o indeterminado, não podendo ser possuído, mas apenas narrado. O que significa narrar o indeterminado? Ora, sendo indeterminado, todas as formas de narração do mito são derivações possíveis, são modos determinados de manifestá-lo e nomeá-lo; assim, o mito só se torna acessível quando é nomeado, como nos diz Gadamer: "nomear é como aludir o que se pode narrar". Quanđo nomeamos, apelamos para o sentido velado e o trazemos à luz no ato de nomear. "Pois o nome cumpre sua função genuína ali onde aparece como apelação e apóstrofe. Então os nomes do divino só são plenamente o que são quando alguém apela ao divino". ${ }^{10}$ No ato de apelar ao divino - ao indeterminado - manifestamos a distância que há entre 0 que determinamos, nomeando, e o que queremos nomear e essa distância é insuperável, por isso é uma distância mítica.

7 Cf. Gadamer, Verdad y metodo I, p. 547 ss.

8 Basta ler os diálogos de Platão para perceber quão recheados de mito estão.

9 Cf. Platão, Sofista, 216c.

10 Cf. Gadamer, Mito e razāo, p. 31. 
Uma outra caracteristica fundante do mito é que ele não tem existência própria, mas existe enquanto é narrado. Nisso consiste a sua necessidade de constante atualização; é preciso narrá-lo para torná-lo vivo e potente, é necessário nomeá-lo para mantê-lo presente. ${ }^{11} \mathrm{Com}$ essa característica podemos ver o mito do lado averso; se antes - na teogonia grega - os mitos se manifestavam através dos deuses do Olimpo e, nesse sentido, pareciam preexistirem aos humanos, hoje, quando os olhamos, ou melhor, os escutamos de dentro, percebemos que são eles que carecem dos homens para sobreviver, pois sem a constante atualização que se dă pela narração, eles seriam esquecidos. É claro que aqui uma outra questão se põe: por que os homens não vivem sem mitos? A filosofia (hermenêutica) tenta esboçar uma resposta a essa questão dizendo que a especulação é própria da linguagem e enquanto tal é ineliminável, por isso, quando especulamos nos damos conta da nossa finitude e dos limites da nossa compreensão que nos abrem o indeterminado. É nesse sentido que a recuperação do mito não é apenas a aceitação do seu valor religioso, dentro e fora das religiões, mas é também a aceitação de que $o$ sentido do mundo se revela lingüisticamente e que é próprio da linguagem apontar para além da experiência, mas sem prescindir dela.

As duas características citadas: o mito não tem paternidade - pertence à indeterminação - e 0 mito não tem existência própria, leva-nos à pergunta pela condição de acesso ao mítico. Aqui encontramos sua terceira característica fundamental: o mito se configura na estrutura da narração. É preciso, então, desvendar essa estrutura para explicitar o lugar do acontecimento mítico.

Uma narração envolve três elementos indispensáveis: o narrado, o narrador e o ouvinte. No círculo da compreensão de um mito, o narrador estimulado pela sede do ouvinte, inicia o processo de desdobramento do mito; no entanto, o mito, antes dobrado, é indeterminado, e isso significa que o narrador não está relatando uma história que já está pronta e acabada - porque a história só se efetiva como desdobramento - mas, no ato de narrar, o próprio narrador produz novas variações do narrado ou, pode-se dizer, o narrado se desdobra de múltiplos modos. Assim, o narrador se encontra diante de duas alteridades: o mito, que está sendo nomeado e a quem o narrador apela para compreender-se e fazer-se compreender, e o ouvinte, que também precisa compreender a narração e, por isso, impõe limites ao narrador, provocando uma tensão entre o mito e a performance do narrador.

O que se estabelece no círculo da compreensão do mito é que o mito não é sem narração; do mesmo modo, pode-se dizer que ele não sobrevive sem um horizonte aberto a sua compreensão. Somente na abertura que se projeta ao infinito 0 mítico acontece enquanto indeterminação. Essa abertura que se projeta ao infinito é o ouvinte, ou melhor, são todos os ouvintes potenciais de uma narração mítica; em cada um deles o mito acontece de uma forma variada, porque o ouvinte é marcado pela historicidade. Do mesmo modo, cada narrador de um mito projeta o narrado num determinado horizonte de compreensão - horizonte ao qual ele mesmo pertence. Desse modo, no ato de narrar se dá um processo recíproco.

11 As religiões praticam com regularidade a atualização dos seus mitos através dos rituais, dos quais faz parte a narração, a nomeação apelativa que toma presente o mito. Podemos tomar como exemplo a liturgia cristã que se renova atualizando o "mistério" da encarnação, morte e ressurreição do Cristo. 
"Ninguém pode narrar se não tem alguns agradecidos ouvintes que o acompanhem até o final. O narrar nunca é um informe exaustivo do que se pode narrar, como ocorre com o protocolo. Implica liberdade para selecionar e liberdade na eleição dos pontos de vista convenientes e significativos. Justamente isso converte a narração em uma espécie de testamento anônimo". ${ }^{12}$

Percebemos que a indeterminação que caracteriza o mito é reproduzida no processo de narração; cada narrador é livre para proclamar uma variação do mito narrado, sem a responsabilidade de dizer a verdade, pois a verdade do mito não consiste na autenticidade da narração, mas na experiência que ela provoca. "Naturalmente, o verdadeiro não é, portanto, a história narrada mesma, que pode ser contada de distintos modos, mas sim o que acontece nela; o verdadeiro não é simplesmente o referido, que sempre estaria submetido à verificação, mas sim o fato presente nele". ${ }^{13}$ Por isso, o narrador não se põe como testemunha autêntica do "acontecimento" que está sendo narrado - não há testemunhas para ele -, mas se coloca como um ouvinte escolhido - por um deus ou uma musa - e encarregado de passar à frente aquilo que ouviu em um momento anterior. Não há narração autêntica de um mito, pois todas as narrações são variações de uma mesma lenda e, nesse sentido, todos os ouvintes se tomam anônimos divulgadores, atestando, por sua interpretação, a autêntica "indeterminação" do mito. ${ }^{14}$

A verdade mesma do mito é sua indeterminação. Aqui não reside sua debilidade, mas sim sua força especulativa. Como não se trata de uma história documental que é mais autêntica, quanto mais se lhe é fiel, não se pretende possuir, por conseguinte, o narrado, mas compreendê-lo e experimentá-lo; então, a força do mito é sua abundância, sua inesgotável fonte de sentido. Na verdade, em vez de contar a história humana como a execução de um programa prefigurado pelos deuses, como se o destino da humanidade já estivesse escrito, a narração mítica nos convida a tomar parte da história e, mais do que isso, mostra que não há história sem a nossa participação. Apesar da narração mítica tratar de algo acontecido no passado, ela sempre desemboca no presente, por isso, "quando as narrações retrocedem até o distante começo, até o primeiro princípio do mundo, estão se referindo, não obstante, inequivocamente, à duração de nosso munđo e se referem a nós mesmos neste mundo". ${ }^{15}$ Assim, a história que nos é narrada é a nossa própria história, épica e trágica: uma longa viagem de vida e morte, um caminho de angústia e de busca de sentido. O mito, especialmente o trágico, proporciona-nos a radical experiência da finitude. ${ }^{16}$

12 Cf. Gadamer, Mito e razão, p. 32.

13 Cf. Gadamer, Mito e razão, p. 64.

14 A narração mítica conta uma história que precisa ser "rememorada", mas que já não pode ser demonstrada com exatidão científica. Todas as determinações dessa história originária são contingentes, posto que são variantes possiveis, mas jamais esgotáveis pelo pensamento. 0 rememorado na narração mítica está marcado pela especulação.

15 Cf. Gadamer, Mito e razão, p. 34

16 É interessante notar que mesmo a morte não se constitui como limite do mito, pois, apesar da morte o mito permanece indeterminado nas asas de outros mitos que nos conduzem à vida pósmorte. Neste ponto, a mitologia não se deixa cercar pela racionalidade controladora, mas, ao contrário, convida a razão a acompanhá-la na saga do indeterminado, e ali onde a razão freia a fé religiosa acontece. 
Há um espanto latente no mito, mais originário que o espanto explícito da pergunta filosófica. Quando abrimos nossos ouvidos para escutar uma narração mítica, já nos colocamos como parte da comunidade na qual a história narrada tem ressonância; não estariamos dispostos a escutar se, de alguma forma, já não estivéssemos sensibilizados. Ora, o mito quando faz parte da vida de uma comunidade lingüística, de alguma forma conta, junto com a história narrada, a história da própria comunidade. Quanto mais vivo é o mito, mais ele toma parte da vida de um povo. Assim, a história narrada deixa de ser apenas a história de deuses e de outros homens e passa a ser, também, a história da comunidade e de cada membro. Nisso consiste o grande espanto latente: o mito conta a minha história, conta uma história da qual tomo parte porque já pertenço a ela desde sempre, na tradição da qual sou filiado. O mito me torna parte de uma unidade, vincula-me com a universalidade do mundo, mas, ao mesmo tempo, faz-me viver uma experiência única, que ninguém pode viver por mim: a experiência da distância do passado e do futuro, daquilo que devo rememorar para manter vivo e antecipar para tornar viável. O mito fecunda a transcendência e a especulação, na medida que me vincula e, ao mesmo tempo, distancia-me da história narrada. O espanto originário trazido pelo mito é o de que sou parte de uma longa história, que pertenço ao tempo e o tempo me marca definitivamente. O mito me diz que não sou um rebento sem paternidade, mas que sou filho de um mundo (de sentido) do qual posso compartilhar.

O logos explicita o espanto tácito no mito. O perguntar, nesse sentido, não é mais originário do que o momento anterior que torna a pergunta possivel; pelo contrário, a pergunta já é uma exposição, ela é o "dito", enquanto o mito é o que já estava posto antes de ser dito; o "dito" é uma determinação possível do indeterminado, do in-dizivel. O mundo de sentido do qual somos parte e compartilhamos, enquanto comunidade lingüistica, já é uma resposta antes de qualquer perguntar, uma resposta silenciosa, tecida pela história, na tradição em que vivemos. O grande espanto da filosofia, aquele que quebra o silêncio do mundo e coloca a pergunta pelo sentido do ser, é um espanto tardio. A pergunta filosófica atesta a distância que separa aquele que pergunta de qualquer resposta possivel. A resposta está no mundo, mas não trazemos o mundo nas mãos, não o possuímos como um objeto, mas, ao contrário, somos possuídos pela história e estamos cercados pela linguagem. ${ }^{17}$ A pergunta filosófica é, portanto, um incessante perguntar, pois especula sobre o sentido e, desse modo, pergunta pelo lugar que ocupado no mundo - chão sempre novo e carente de respostas.

A pergunta filosófica acontece no diálogo e se dirige ao outro; busca respostas, mas não esgota suas possibilidades, apenas abre novos caminhos. Quando acontece a pergunta, rompemos com o habitual, quebramos o silêncio da tradição que nos chega como resposta e instalamos a distância entre pergunta e perguntado, pois a filosofia pergunta sempre para além dos limites estabelecidos pela experiência. A dúvida mostra, antes de qualquer resposta, que todas as anteriores e silenciosas respostas acolhidas também podem se tornar perguntas. E porque dirijo a minha pergunta ao "outro", que, como eu, pertence ao mesmo mundo

17 Cf. Gadamer, Mito e razão, p. 121. 
histórico e temporal e, por isso, compartilha comigo a experiência da finitude, compreendo que sua resposta, por mais satisfatória que seja, não fundamenta definitivamente a minha pergunta, mas apenás me abre novos caminhos ou, talvez, aponta-me um caminho sem saída, o que poderá me fazer, mais tarde, voltar atrás, para reencontrar as "sendas perdidas".

Para Gadamer:

\begin{abstract}
"A filosofia não conhece frases verdadeiras que alguém tenha só que dẻiender e demonstrar como as mais fortes. O filosofar é, para além disto, uma constante revisão que ele mesmo faz de todos os seus conceitos, assim como um diálogo é uma constante revisão que alguém faz graças à resposta do outro. Por isso, não há propriamente textos da filosofia, no sentido em que falamos de textos literários, ou de textos legais ou da Sagrada Escritura. Assim como a experiência dos homens se forma sob as condições históricas de suas vidas e de seus destinos, assim se formam as palavras e as respostas que permitem colocar novas perguntas. A história da filosofia é, por conseguinte um diálogo interrompido consigo mesmo. Os filósofos não têm textos porque, como Penélope, estão tecendo constantemente seu véu, preparando-se novamente para o regresso à pátria do verdadeiro". ${ }^{18}$
\end{abstract}

O mito narra uma história que se constitui como um diálogo continuado, sem interrupção e sem fim. Os tempos imemoriais de onde procedem as narrações míticas nos lembram que não há ruptura do diálogo já desde o passado; da mesma forma, a transposição da morte, através do culto aos mortos, afirma que, também no futuro, o diálogo deve continuar. O mito não suporta a interrupção do diálogo, por isso, o pensamento mítico "dá voz" aos que a morte cala para que o diálogo continue. As respostas, já não são dadas por alguém, mas por uma pluralidade de vozes vindas da "tradição", dando ao pensamento a possibilidade de responder-se a si mesmo. ${ }^{19}$

A filosofia, por outro lado, é um diálogo interrompido consigo mesmo e, desse modo, o filósofo é precursor da finitude. $\mathrm{O}$ antes - indeterminado - e o depois - o trágico, anunciado pela morte, traz o filósofo para o presente e, desse lugar, ele se pergunta pelo sentido do ser e de ser. Marcado pela experiência da finitude, ele se torna um revisor contumaz de respostas e conceitos e abre novos caminhos, com novas perguntas. A atividade da filosofia, através da permanente tessitura de seu texto, não é capaz de livrar o filósofo da angústia visceral do silêncio da morte, que ele parece querer evitar. O filósofo sabe que a morte cala a filosofia e, por isso, faz-se precursor da finitude no diálogo filosófico. Mas é preciso ter claro que somente um diálogo autêntico não pode ser silenciado; calar o diálogo é decretar o fim da filosofia.

18 Cf. Gadamer, Mito e razão, p. 117-118.

19 Um diálogo que não se dá com um verdadeiro "outro" não é diälogo filosófico, pois nele não cabem perguntas, mas é um monólogo que exclui o "outro", e o exclui porque este não é suportável pela ameaça que causa. Por isso, por não suportar a ruptura do diálogo, causada pela morte, o mito continua dialogando no silèncio, sem interlocutores. 


\section{Referências bibliográficas}

GADAMER, H. Georg. Verdad y Metodo I. Salamanca (Espanha), 1993.

. Mito y Razón. Barcelona (Espanha): Paidós, 1997.

.El inicio de la filosofia occidental. Barcelona (Espanha): Paidós, 1995.

OLIVEIRA, Manfredo A. de. Reviravolta lingüistico-pragmática na filosofia contemporânea. São Paulo:

Loyola, 1997.

PLATÃO. A República, 6. ed.. Lisboa (Portugal): Fundação Calouste Gulbenkian, 1990.

ELIADE, Mircea. O mito do eterno retorno. Lisboa (Portugal): Edições 70, 1993.

. Tratado de história das religiōes. São Paulo: Martins Fontes, 1993.

VERNANT, Jean-Pierte. Mito e religião na Grécia antiga. São Paulo: Papirus, 1992. 